Matters arising

\section{Labial adhesions after genital herpes infection}

Sir,

Walzman and Wade ${ }^{1}$ report a case of labial adhesions after genital herpes infection and note that only three cases have been documented previously. We have recently seen a similar case.

A 19 year old girl was referred by her general practitioner with a 4 day history of vulval soreness and dysuria. Genital examination revealed a severe vulvitis with ulceration and oedema. A presumptive diagnosis of primary genital herpes was made which was later confirmed by tissue culture. Saline bathing was advised and she was commenced on standard doses of oral acyclovir and trimethoprim. She returned the following day complaining of an inability to pass urine and was admitted to the ward. The oral acyclovir was increased to $400 \mathrm{mg}$ qds. There was no clinical evidence of a sacral radiculitis and she passed urine in the bath after using topical lignocaine. She was discharged after 5 days and on review in the out patient clinic 2 days later, it was noted that although the vulvitis had settled, she had developed a $1 \mathrm{~mm} \times 2 \mathrm{~mm}$ labial adhesion. It was suggested that she gently tease the adhesions apart whilst bathing and within 4 days normal anatomy had been restored.

In contrast to the recent report, our patient was commenced on antiviral therapy within 4 days of onset of the lesions and this clearly did not prevent the formation of adhesions. Labial adhesions may develop as a consequence of severe ulceration and/or superadded infection and although rare do occur.

We have seen one other case in the past 6 months but are unsure of the clinical outcome as the patient defaulted from follow up. To prevent this complication we recommend that women with primary genital herpes be encouraged to separate the labial folds during saline bathing. Paraffin gauze (Paratulle) may also be interposed between adjacent vulval ulcers. If adhesions develop, a trial of gradual labial separation by the patient using either plain or lignocaine gel should be considered, prior to a more radical procedure.

C A Bowman $P$ A De Silva E F Monteiro

Dept of Genitourinary Medicine, The General Infirmary At Leeds, Great George Street, Leeds LS1 3EX, UK
Reference

1 Walzman M, Wade AAH. Labial adhesions after genital herpes infection. Genitourin Med 1989;65:187-8.

Labial adhesions after genital herpes infection

Sir,

Walzman and Wade report a case of labial adhesions following acute Herpes simplex virus (HSV) vulvitis,' apparently the third reported case worldwide. In the last 10 years I have treated three such cases, all following acute HSV vulvitis. Lack of saline bathing during the acute phase was noted in all cases. I managed all three women with separation of the adhesions using gentle blunt dissection after topical then infiltrated local anaesthesia early during follow-up. Anatomic and functional results were excellent. More minor adhesions in the region of the posterior vaginal introitus are seen following episiotomy and other perinatal perineal trauma. I have also taken part in the management of a woman with transverse mid and upper vaginal adhesions associated with mucosal lichen planus of the vagina. Management consisted of initial introduction of the use of dilators followed by blunt dissection of the adhesions under general anaesthesia, followed by continuing use of dilators, with intra-vaginal administration of clotrimazole-hydrocortisone $1 \%$. Recovery of sexual function occurred.

A further recent case was that of a woman who initially presented with an anatomically normal cervix and cervical intra-epithelial neoplasia. The lesion was treated with Semm coagulation but super-infection of the ectocervix was diagnosed at 7 days follow-up and treated with antibiotics. Six months later colposcopy revealed a double os, formed by a $5 \mathrm{~mm}$ wide bridge from anterior to posterior lip. The two canals merged $2.5 \mathrm{~mm}$ from the apparent surface. In view of recurrent cervical intraepithelial neoplasm and menorrhagia treatment was by hysterectomy. Adhesions in the female genital tract can therefore arise in a number of ways, although HSV infection is probably nowadays a common cause. It seems likely that these genito-urinary medical curiosities are underreported.

Dept of Genitourinary Medicine

$C J N$ Lacey

The General Infirmary,

Leeds LS1 3EX, UK

\section{Reference}

1 Walzman MW, Wade AAW. Labial adhesions after genital herpes infection. Genitourin Med 1989;65:187-8.
Genitourin Med 1989;65:401-403

\section{Acute urethritis due to Neisseria meningitidis}

Sir,

We read with interest the article of Dr Wilson and colleagues (Genitourin Med 1989;65: 122-3) which described a case of acute urethritis due to $N$ meningitidis group $\mathrm{A}$ acquired by orogenital contact. We saw a similar couple during March this year. A 25 year old heterosexual man presented with a urethral discharge and dysuria of one week duration. He admitted to fellatio with his girlfriend. A gram stained specimen showed polymorphonuclear leucocytes with intracellular gram-negative diplococci. Further urethral and throat specimens were cultured on Modified New York City (MNYC) medium. He was told that the probable diagnosis was gonococcal infection and was treated with single oral dose of $250 \mathrm{mg}$ ciprofloxacin. His girlfriend was seen on the same day and specimens were taken from her throat, urethra, endocervix and rectum to culture for neisseria species on MNYC medium. She had an endocervical culture for Chlamydia trachomatis and microscopy and culture of the vaginal specimens. Both of them denied other sexual partners for more than a year.

The results of the microbiologic assays showed a growth of $N$ meningitidis from the man's urethral specimen and the woman's throat specimen. Both isolates were not groupable and not typable and both had identical antibiotic sensitivities. Her specimens failed to grow $N$ gonorrhoeae, $C$ trachomatis, candida species and a wet film examination of her vaginal specimen did not show $T$ vaginalis. $N$ meningitidis was not isolated from her urethral and cervical specimens. Repeat testing one week later confirmed the original findings prior to treatment.

His urethritis resolved with single dose of ciprofloxacin and he remained asymptomatic on two further follow up visits. Even though we did not exclude other pathogens as the cause of his urethritis its complete resolution with a single dose of ciprofloxacin and the absence of other pathogens except $N$ meningitidis in his partner's specimens favour $N$ meningitidis as the aetiological agent for the urethritis.

A peak carriage rate of $N$ meningitidis of over $20 \%$ in young adults was found in a large community survey. ${ }^{1}$ In a study of 1025 female patients attending a Genitourinary Medicine clinic in London $70 \%$ of them admitted practising fellatio. ${ }^{2}$ This further confirms the importance of excluding $N$ meningitidis as a cause of urethritis when gram negative intracellular diplococci are found on microscopy and Neisseria species 
are identified following the culture of ureth- as the smear did not differ significantly ral material from men.

\section{K Shanmugaratnam} R S Pattman

Dept of Genitourinary Medicine,

Newcastle General Hospital,

Newcastle upon Tyne, NE4 6BE, UK

\section{References}

1 Cartwright KAV. Meningococcal meningitis. Br J Hosp Med 1987;38:516-24.

2 Evans BA, Bond RA, Macrae KD. Sexual behaviour in women attending a genitourinary medicine clinic. Genitourin Med 1988; 64:43-8.

\section{Ayre v Aylesbury cervical spatulas}

Sir,

Our experience with the use of the Ayre and Aylesbury spatulas for taking cervical smears from women attending a genitourinary medicine clinic is similar to that of Dr Goorney and colleagues.' Cervical smears obtained with Ayre spatula from 406 women who attended the department of genitourinary medicine in Newcastle during the first quarter were compared with those obtained with Aylesbury spatula from 566 women who attended during the second quarter of this year. Women who had smears taken as follow up to previous abnormal smears were not included in this analysis. If a woman had more than one smear taken during the six month study period only the first smear was included. Both groups were similar in age with mean ages of $25 \cdot 1$ and 25 years. The incidence of sexually transmitted diseases diagnosed during the same quarter

between the two groups. Endocervical cells were found significantly more often with the spatula, especially if the smear was normal (table). There was no significant difference between the proportions of epithelial abnormalities with or without endocervical cells diagnosed with the two spatulas. Altogether $82(20.2 \%)$ of smears obtained with the Ayre spatula and $91(16.4 \%)$ of smears obtained with Aylesbury spatula had epithelial abnormalities $(p>0 \cdot 1)$. Unlike Dr Goorney and colleagues we did not see a significant difference between the proportions of unsatisfactory smears in the two groups.

The apparent lack of association between the detection of endocervical cells and that of abnormalities needs to be interpreted with caution as endocervical cells may not after all be the right indicator of adequacy of sampling. ${ }^{23}$ Perhaps the quality of smears (and the efficacy of spatulas) should be assessed using multiple criteria so that the better sampling method can be found.

K Shanmurgaratnam* K Sankar*

$V$ Wadehrat

Departments of Genitourinary Medicine, ${ }^{*}$ and Cytopathology†

Newcastle General Hospital,

Westgate Road,

Newcastle upon Tyne,

Tyne and Wear NE4 6BE, UK

\section{References}

1 Goorney BP, Lacey CJN, Sutton J. Ayre v Aylesbury cervical spatulas. Genitourin $\mathrm{Med}$ 1989;65:161-2.

2 Kivlahan C, Ingram E. Papanicolaou smears without endocervical cells. Are they inAylesbury spatula than with the Ayre

Comparison of 962 women whose smears were taken with Ayre or Aylesbury spatulas (figures refer to numbers (percentages) of women with the given finding)

\begin{tabular}{|c|c|c|c|}
\hline & $\begin{array}{l}\text { Ayre } \\
(n=406) \\
(\text { mean age }=25 \cdot 1)\end{array}$ & $\begin{array}{l}\text { Aylesbury } \\
(n=556) \\
(\text { mean age }=25 \cdot 0)\end{array}$ & Difference \\
\hline $\begin{array}{l}\text { Normal smear } \\
\text { with endocervical cells } \\
\text { Non dyskaryotic epithelial abnormality } \\
\text { with endocervical cells } \\
\text { Dyskaryotic smear } \\
\text { with endocervical cells } \\
\text { Unsatisfactory smear } \\
\text { Total } \\
\text { Smear with endocervical cells } \\
\text { Lower genital tract infection/s† } \\
\text { Lower genital tract infection/s-Group A* }\end{array}$ & $\begin{array}{l}311(76 \cdot 6) \\
130 \\
65(16 \cdot 1) \\
28 \\
17(4 \cdot 1) \\
5 \\
13(3 \cdot 2) \\
406 \\
163(40 \cdot 1) \\
214(53 \cdot 7) \\
134(33)\end{array}$ & $\begin{array}{l}451(81 \cdot 1) \\
247 \\
71(12 \cdot 8) \\
34 \\
20(3 \cdot 6) \\
12 \\
14(2 \cdot 5) \\
556 \\
293(52 \cdot 7) \\
323(58 \cdot 1) \\
205(36 \cdot 9)\end{array}$ & $\begin{array}{l}\text { NS } \\
\text { p }<0.001 \\
\text { NS } \\
\text { NS } \\
\text { NS } \\
\text { NSt } \\
\text { NS } \\
\text { p }<0.001 \\
\text { NS } \\
\text { NS }\end{array}$ \\
\hline
\end{tabular}

*One or more of syphilis, gonorrhoea, chalmydial infections, genital herpes, condyloma accuminata and trichomoniasis.

tFisher's exact probability value $=0 \cdot 124$.

†Includes Group A. adequate? Acta Cytol (Baltimore) 1986;3 258-60.

3 Woodman CBJ, Williams D, Yates M, et ait Indications of effective cytological samplin of the uterine cervix. Lancet 1989;ii:88-90.

\section{Allergic reactions to rubber condoms}

Sir,

Allergic reactions to condoms are infrequently reported in the literature. Antio idants and other rubber chemicals are potential allergens and an attempt has been made to make "hypoallergenic" condoms by was ing out rubber additives.' In a recent paper $\vec{m}$ Genitourinary Medicine, Rademaker and Forsyth stated that rubber latex itself rare gives rise to allergic problems.' In contrast this view, we have shown that allergy to latex is rather common among people using suf gical or household rubber gloves and that condoms may also cause symptoms due to allergy. ${ }^{23}$ The frequency of latex allerg among glove-using hospital employees is đ\$ high as $3 \%$ in Finland and increasing aware ness has revealed this allergy in many othe्ष countries. ${ }^{4}$ The allergen is latex protem derived from the rubber tree and existing $\overrightarrow{i B}$ manufactured products such as gloves, cofo doms and balloons. The symptoms include local urticarial reactions but also systema symptoms such as asthma. Moreover, alle gic patients have exhibited anaphylact reactions during delivery or vaginal examif ation from the latex gloves worn by doctog and nurses. ${ }^{5}$

The manufacturing process is similar f both condoms and surgical latex gloves. Therefore, condoms also seem to be a potem tial source of latex allergy. We recentiy described seven (six females, one male) patients allergic to latex who had experie ced local symptoms from contact with co doms during or immediately after inter. course. ${ }^{3}$ An anaphylactic reaction from col dom usage was recently reported by Taylor et al showing also that condom allergy can life-threatening. ${ }^{6}$ We examined 16 differe condom brands and found great differences. in their allergenity. ${ }^{3}$ Three of the most allew genic brands originated from the sanpe manufacturer suggesting that the amount $o f$ latex protein persisting in condoms is depent dent on the manufacturing process.

The immediate latex allergy from gloves and condoms is a newly described phe omenon which may easily escape clinic diagnosis. Atopic people are prone to this IgE-mediated allergy which can be verified by prick testing or latex RAST (Pharmach Diagnostics, Uppsala, Sweden). ${ }^{37}$ Simulta eous delayed allergy to rubber chemicals $\frac{}{\mathrm{as}}$ 